\title{
Recommendations for Sampling of Tank 18 in F Tank Farm
}

\author{
Eugene P. Shine
}

December 14, 2009

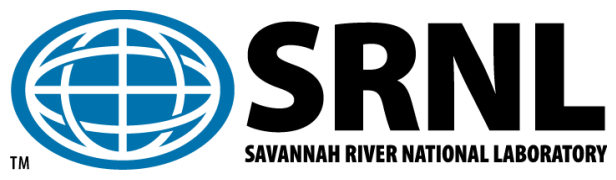

Savannah River National Laboratory

Savannah River Nuclear Solutions

Savannah River Site Aiken, SC 29808

This document was prepared in conjunction with work accomplished under Contract No. DE-AC09-08SR22470 with the U.S. Department of Energy 


\section{DISCLAIMER}

This work was prepared under an agreement with and funded by the U.S Government. Neither the U. S. Government or its employees, nor any of its contractors, subcontractors or their employees, makes any express or implied: 1. warranty or assumes any legal liability for the accuracy, completeness, or for the use or results of such use of any information, product, or process disclosed; or 2. representation that such use or results of such use would not infringe privately owned rights; or 3. endorsement or recommendation of any specifically identified commercial product, process, or service. Any views and opinions of authors expressed in this work do not necessarily state or reflect those of the United States Government, or its contractors, or subcontractors. 


\section{Reviews and Approvals:}

Author:

E. P. Shine, Author Applied Computational Engineering and Statistics

\section{Review/Approval:}

T. B. Edwards, Technical Reviewer Applied Computational Engineering and Statistics

G. D. Thaxton, Closure Product Engineering Savannah River Remediation

B. A. Martin, Closure \& Disposal Determination Savannah River Remediation

F.M. Pennebaker, Manager

Advanced Characterization \& Processing

P.L. Lee, Manager

Applied Computational Engineering and Statistics
Date

$\overline{\text { Date }}$

Date

Date

Date

Date 


\section{TABLE OF CONTENTS}

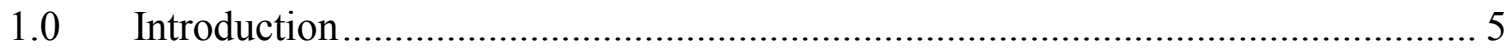

2.0 Previous Sample Plans and Results ............................................................ 5

3.0 Recommendations to Complete Sampling ...................................................... 7

3.1 Analyte Concentration in the Residual Floor Material ..................................... 7

3.2 Upper Confidence Limits on Concentrations......................................................... 8

3.3 Computation of Analyte Concentration Confidence Limits .................................. 9

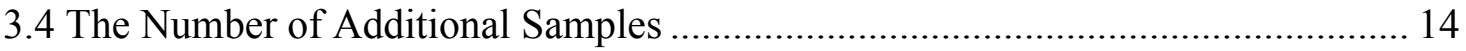

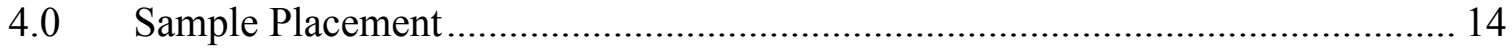

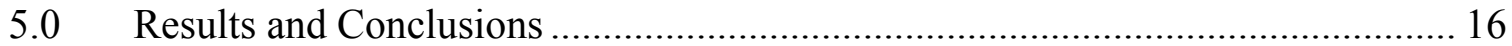

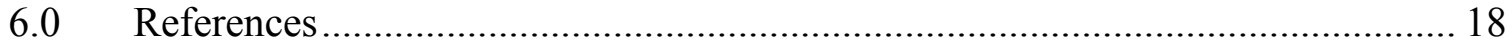

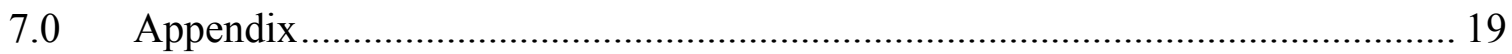

\section{LIST OF TABLES}

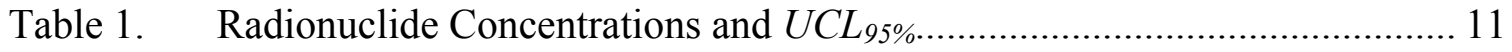

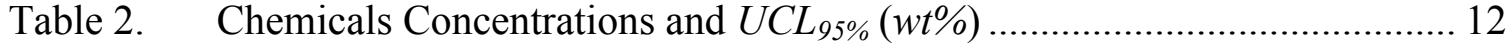

Table 3. Sample Information from the Mantis Rover Samples ................................. 19

Table 4. Constituents Below Detection Limits .................................................... 21

Table 5. Description of Evaluated Radionuclides.................................................. 22

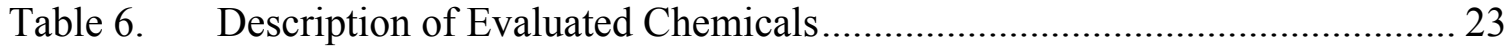

\section{LIST OF FIGURES}

Figure 1. Layout for additional sampling locations in Tank 18 ............................. 16

Figure 2. $\quad$ Previous Mantis rover sampling locations in Tank 18 ............................... 24

Figure 3. Uncertainty per Additional Samples (All Analytes) ….............................. 25

Figure 4. Uncertainty per Additional Samples (0-25\%) ............................................. 25

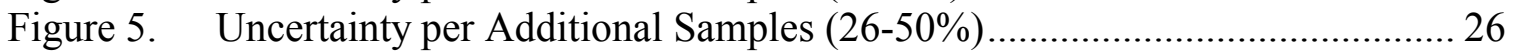

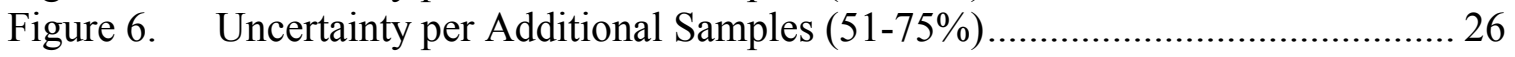

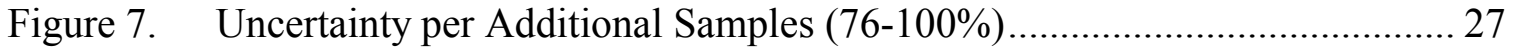

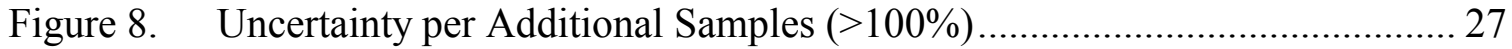




\subsection{INTRODUCTION}

Representative sampling is required for characterization of the residual floor material in Tank 18 prior to operational closure. Tank 18 is an 85-foot diameter, 34-foot high carbon steel tank with nominal operating volume of 1,300,000 gallons. It is a Type IV tank, and has been in service storing radioactive materials since 1959. Recent mechanical cleaning of the tank removed all mounds of material. Anticipating a low level of solids in the residual material, Huff and Thaxton [2009] developed a plan to sample the material during the final clean-up process while it would still be resident in sufficient quantities to support analytical determinations in four quadrants of the tank. Execution of the plan produced fewer solids than expected to support analytical determinations in all four quadrants. Huff and Thaxton [2009] then restructured the plan to characterize the residual floor material separately in the North and the South regions: two "hemispheres."

This document provides sampling recommendations to complete the characterization of the residual material on the tank bottom following the guidance in Huff and Thaxton [2009] to split the tank floor into a North and a South hemisphere. The number of samples is determined from a modification of the formula previously published in Edwards [2001] and the sample characterization data for previous sampling of Tank 18 described by Oji [2009]. The uncertainty is quantified by an upper 95\% confidence limit $\left(U C L_{95 \%}\right)$ on each analyte's mean concentration in Tank 18 . The procedure computes the uncertainty in analyte concentration as a function of the number of samples, and the final number of samples is determined when the reduction in the uncertainty from an additional sample no longer has a practical impact on results.

\subsection{PREVIOUS SAMPLE PLANS AND RESULTS}

Early sampling plans to characterize the residual material in tanks scheduled for closure include a statistically-based framework by Edwards [2001] for Tanks 18 and 19, and a more recent sampling application of this framework by Edwards and Shine [2008] for Tanks 5 and 6 . The formulation of sampling uncertainty in these reports allows for separate phases such as separate mounds of radioactive material and distinct nonoverlapping regions of the tank that could be separately sampled and analyzed once cleanup efforts were completed.

A sampling and analysis plan for Tanks 18 and 19 was drafted by Huff and Thaxton [2009]. The plan focused on obtaining in-process samples using the Mantis rover. During the mechanical cleaning process, residual material from Tank 18 was mobilized and transferred by eduction to a Waste Mix Chamber (WMC) in Tank 7. There the waste was ground by an immersion mill grinder to less than 38 microns. Once sufficiently comminuted, the particles floated upward and into a sampler in the WMC.

The original sampling plan called for two in-process vials (samples) of about $125 \mathrm{~mL}$ each from each of four tank quadrants: Northwest, Northeast, Southwest, and Southeast. 
In addition, a third $125 \mathrm{~mL}$ vial per quadrant was planned as an archival sample as a contingency.

The plan was executed, and the three $125 \mathrm{~mL}$ samples per quadrant were sent to the Savannah River National Laboratory (SRNL) for analysis. The samples did not yield an adequate quantity of solids to support all of the analytical tests in all four quadrants. Appendix Table 3 lists the amount of solids estimated by SRNL to be in the samples. The entire suite of analytical tests requires approximately 30 grams of solids, although a partial list of key analytes requires only a few grams of solids. As a result, Huff and Thaxton [2009] report that the sampling plan was revised by partitioning the tank into a North and a South hemisphere.

Appendix Table 3 lists the Mantis rover samples that have been taken from the residual material on the tank floor. The sampling locations had been identified from viewing video of the Mantis rover in operation. The solids material from the sample vials taken from the sampling location northwest of the center riser, Sample Site 4 in the table, have been consolidated and analyzed, while the North hemisphere Mantis sample vials corresponding to Sample Sites 1 and 2 have been archived.

The South Mantis rover sample vials ${ }^{1}$ from the location near the west riser, Sample Site 3 in the table, have been archived, so no analyte information is currently available from that sample location. Multiple sampling vials were obtained from each sampling site on the floor of Tank 18. The weight of the solids in each of these vials is reported in appendix Table 3. The contents of all of the vials listed as having been obtained within Sampling Site 4, "NW of the center riser" in appendix Table 3, were combined into a single sample of solids for analysis. Although the solids in the vials from Sampling Site 4 were consolidated, the material came from a relatively compact floor region. So from the perspective of this report, this is considered a sample of material from a single location, rather than a spatially-composited sample. The vials in Sample 5 in appendix Table 3, except where noted as archived, were consolidated from three different southern sampling sites (5A, 5B, and 5C) into a single composite sample of solids for analysis. However, 2/3 of the solids in Sample 5 came from a single location, and nearly all of the remainder came from a second location. So the results from Sample 5 are expected to be weighted toward the concentrations of analytes in the region that contributed $2 / 3$ of solids, rather than an average of equally-weighted spatially-distributed regions of the tank floor.

In addition to the Mantis rover samples, a quality assurance sample was obtained near the Northeast Riser by scraping material from the tank floor. The amount of solids in the floor scrape sample was sufficient to support a subset of key analytes. This sample was compared to Mantis rover samples from the North hemisphere in order to ensure that the rover method did not alter the concentrations of the analytes in the solids. The samples were shown to be different just based on analytical uncertainty. However, there may be no

\footnotetext{
1 The sampling campaign with the Mantis rover had originally produced solids from four sampling sites labeled North and three sampling sites labeled South. However, inspection of the video has resulted in a reclassification of the North sample near the west riser as a South Mantis sample, yielding three North and four South Mantis samples.
} 
difference once sampling variability is considered. The additional floor scrape samples that are recommended in each hemisphere will permit a valid comparison that includes analytical uncertainty and sampling variability.

\subsection{RECOMMENDATIONS TO COMPLETE SAMPLING}

The sampling strategy for Tank 18 to this point in time takes into account possible differences between the North and the South hemispheres, Huff and Thaxton [2009]. A consistent path forward is to determine the quantity of various analytes in the residual floor material separately for the North and South regions. The total residual material is then the sum of the material in the two regions. Later, if sampling results show that the residual material is similar in the two hemispheres, then the sampling data can be consolidated into a single unit for the entire floor area.

The first stage of the sampling strategy is to determine the number of samples in each hemisphere needed to characterize the concentration of analytes in the residual material on the tank floor. A subsequent phase specifies the locations of additional samples, if deemed necessary, to successfully complete the inventory of the residual material on the floor of Tank 18. This section outlines the formula for the concentration of residual material for any particular analyte. The following section describes how the number of samples is to be determined.

\subsection{Analyte Concentration in the Residual Floor Material}

No distinct mounds of material appear to be left after final cleaning operations. However, the material is stratified into $(i=1)$ North and $(i=2)$ South hemispheres. The formula for the estimated concentration of an analyte for the entire tank floor is

$$
A=\frac{\sum_{i=1}^{2} \bar{a}_{i . .} \bar{\rho}_{i} V_{i}}{\sum_{i=1}^{2} \bar{\rho}_{i} V_{i}},
$$


where $\bar{a}_{i . .}$ is the mean ${ }^{2}$ measured concentration for analyte $a$ in the residual material from stratum $i, i=1,2 ; \bar{\rho}_{i}$ is the mean sample density in stratum $i, i=1,2$; and $V_{i}$ is the volume of residual floor material in stratum $i, i=1,2$. The analyte is measured either wet or dry. Sample material is centrifuged, and the liquid portion is decanted to achieve a wet state. An additional baking step is performed to dry some of the samples. Consequently, either a wet or a dry density is applicable depending on the method of sample preparation. Nearly all laboratory subsamples are in the same state of preparation, wet or dry, when measured for a given analyte. In this report, the estimates of both the wet and dry densities were obtained from Thomas [2005]. The density of the samples did not appear to systematically vary by hemisphere, so the density data was pooled in order to obtain a single estimate for the entire tank. The wet density is 1.4 (wet) $\mathrm{g} / \mathrm{mL}$ with a standard deviation of 0.005 (wet)g/mL, and the dry density is 0.97 (dry)g/mL with a standard deviation of 0.0046 (dry)g/mL, based on five samples: FTF-213, FTF-214, FTF-216, FTF-228, and FTF-229.

The volumes of the residual material in the North hemisphere, approximately 2,000 gallons, and South hemisphere, approximately 1,900 gallons, was provided by Ludwig [2009]. The volumes were converted to milliliters $(\mathrm{mL})$ by multiplying by 3.7854118 liters/gallon *1,000 mL/liter. The volume estimates are considered to be best conservative estimates for the residual material. Therefore, volume uncertainty was not included in the total uncertainty.

\subsection{Upper Confidence Limits on Concentrations}

A one-sided upper $95 \%$ confidence limit is established for analytes that have supporting data (not all less than detection results, for example). Such a limit establishes a credible upper bound on the mean concentration of analyte $a$ in the residual material on the floor of the tank. The formula for the confidence limit is as follows.

$$
U C L_{95 \%}\{A\}=A+t_{0.95, d f} \sqrt{A^{2} S_{A}^{2}},
$$

where $A$ is the mean concentration of analyte $a$ over the entire tank floor residual and $S_{A}$

\footnotetext{
${ }^{2}$ Subscripts $i, j$, and $k$ on measurement $a_{i j k}$ indicate that it represents measurement $k$ on a sample $j$ from a stratum $i$. A dot (.) in place of a subscript represents the sum of all measurements over that subscript, so $a_{i j}$. represents the sum of all measurements on sample $j$ in stratum $i$ since the dot replaces the $k$, and $a_{i \text {. }}$ represents the total of all measurements over all samples in stratum $i$ since the dots replace $j$ and $k$. A mean is defined by the sum of set of measurements divided by the number of measurements in that set, and is identified with a bar $\left(^{-}\right)$over the italic letter representing a sum of measurements, so $\bar{a}_{i j .}=(1 / m) \sum_{k=1}^{m} a_{i j k}$ and $\bar{a}_{i . .}=\left(1 / n_{i}\right) \sum_{j=1}^{n_{i}} \bar{a}_{i j .}=\left(1 /\left(m n_{i}\right)\right) \sum_{j=1}^{n_{i}} \sum_{k=1}^{m} a_{i j k}$ represent the mean of all
} measurements for just sample $j$ in stratum $i$ and the mean of all measurements in stratum $i, i=1,2$, respectively. 
is the estimated relative standard error of the mean concentration $A$. The $d f$ in equation (2) is the degrees of freedom associated with $S_{A}$, based on $n_{i}-1$ sampling degrees of freedom in each hemisphere $i=1,2$.

At present there are no established upper concentration specifications for analytes, so the $U C L_{95 \%}$ s cannot be compared to such limits in order to establish the adequacy of the number of samples planned to be taken. The $U C L_{95 \%}$ depends on the sample design (stratification), the number of samples in each stratum, and the number of analytical determinations per sample. An increase in the number of samples or an increase in the number of determinations per sample will generally produce a decrease in the $U C L_{95 \%}$. The analytical method and the amount of sample material available for analyses that are also pertinent factors. The incremental effect of one additional sample on reducing the uncertainty in the concentration estimate diminishes as more samples are added. A series of charts and tables has been constructed in order to ascertain the total number of additional samples needed.

In order to place the results on a common scale and more easily visualize the results, each $U C L_{95 \%}$ is converted to a relative uncertainty by taking the ratio of the length of the onesided confidence limit to the mean concentration A for analyte $a$,

$$
\operatorname{RelUCL}_{95 \%}=100 \% \frac{U C L_{95 \%}\{A\}-A}{A}
$$

The relative $U C L_{95 \%}$ is a measure of the uncertainty in $A$ relative to its value; it is equal to $t_{0.95, d f} S_{A}$. The relative $U C L_{95 \%}$ is a better measure than the relative standard error of A, $S_{A}$ since small samples sizes affect the value of $t_{0.95, d f}$ (through its degrees of freedom $d f$ ) as well as through the value of the estimated standard error of $A$.

The standard error of the concentration, $A$, depends on estimates of the concentration error standard deviation (accounts for sample preparation variation as well as measurement error), and the sampling variation within Tank 18. The analytical error standard deviation was determined from available replicate determinations. The sampling standard deviation was approximated by the standard deviation of the sample means. In many cases this meant the sampling standard deviation depended on the difference between the North and South Mantis sample means, the only source of sampling variation available. This is a conservative approach since the North and South hemispheres potentially have systematic differences in concentration. For a few analytes, the use of hemisphere differences may have inflated the sampling error within each hemisphere during the planning process.

\subsection{Computation of Analyte Concentration Confidence Limits}

Table 1 lists all radionuclides that have sufficient measurements to compute an $U C L_{95 \%}$. The table is based on the North and South hemisphere Mantis rover samples and the North hemisphere QA floor scrape sample. The North hemisphere concentration is a 
simple average of the North Mantis and North floor scrape sample concentrations when determinations were performed on both samples; it is equal to the lone sample concentration average, if only one of the two North samples was measured for the analyte. The South hemisphere concentration was based solely on the South Mantis sample concentration average. The estimated tank concentration was an average of the North hemisphere and the South hemisphere concentration averages, weighted for the volume of the residual material in each hemisphere. The concentrations for radionuclides are in $\mu \mathrm{Ci} / \mathrm{g}$. The units of grams in the denominator are either "wet" or "dry", depending on the state of the samples when measured and conform to those reported in Oji [2009]. 
Table 1. Radionuclide Concentrations ${ }^{3}$ and $U C L L_{95 \%}$ for the Baseline Sample Plan (No Additional Sampling) $(\mu \mathrm{Ci} / \mathrm{g})$

\begin{tabular}{|c|c|c|c|c|}
\hline Radionuclide & $\begin{array}{c}\text { Mean Concentration } \\
\text { of North } \\
\text { Hemisphere Samples }\end{array}$ & $\begin{array}{c}\text { Concentration of } \\
\text { the South } \\
\text { Hemisphere Sample }\end{array}$ & $\begin{array}{l}\text { Estimated Tank } \\
\text { Concentration }\end{array}$ & $\begin{array}{l}U C L_{95 \%} \text { for } \\
\text { Concentration }\end{array}$ \\
\hline Am-241 & $3.66 \mathrm{E}+00$ & $3.12 \mathrm{E}+00$ & $3.39 \mathrm{E}+00$ & $5.17 \mathrm{E}+00$ \\
\hline Am-242m & $3.45 \mathrm{E}-05$ & $6.36 \mathrm{E}-05$ & $4.88 \mathrm{E}-05$ & $1.59 \mathrm{E}-04$ \\
\hline Am-243 & $2.14 \mathrm{E}-03$ & $1.85 \mathrm{E}-03$ & $2.00 \mathrm{E}-03$ & $3.25 \mathrm{E}-03$ \\
\hline Ba-137m & $3.33 \mathrm{E}+02$ & $8.60 \mathrm{E}+02$ & $5.92 \mathrm{E}+02$ & $2.39 \mathrm{E}+03$ \\
\hline C-14 & $3.44 \mathrm{E}-03$ & $1.85 \mathrm{E}-03$ & $2.66 \mathrm{E}-03$ & $8.60 \mathrm{E}-03$ \\
\hline $\mathrm{Cm}-242$ & $2.85 \mathrm{E}-05$ & $4.54 \mathrm{E}-05$ & $3.68 \mathrm{E}-05$ & $5.65 \mathrm{E}-04$ \\
\hline $\mathrm{Cm}-244$ & $1.30 \mathrm{E}-01$ & $1.20 \mathrm{E}-01$ & $1.25 \mathrm{E}-01$ & $1.81 \mathrm{E}-01$ \\
\hline Co-60 & $2.09 \mathrm{E}-02$ & $1.76 \mathrm{E}-02$ & $1.93 \mathrm{E}-02$ & $2.91 \mathrm{E}-02$ \\
\hline Cs-135 & $2.08 \mathrm{E}-03$ & $5.66 \mathrm{E}-03$ & $3.84 \mathrm{E}-03$ & $1.62 \mathrm{E}-02$ \\
\hline Cs-137 & $3.61 \mathrm{E}+02$ & $9.08 \mathrm{E}+02$ & $6.30 \mathrm{E}+02$ & $2.42 \mathrm{E}+03$ \\
\hline Eu-154 & $1.53 \mathrm{E}-02$ & $1.46 \mathrm{E}-02$ & $1.50 \mathrm{E}-02$ & $1.82 \mathrm{E}-02$ \\
\hline Ni-59 & $3.82 \mathrm{E}-03$ & $7.33 \mathrm{E}-03$ & $5.55 \mathrm{E}-03$ & $1.84 \mathrm{E}-02$ \\
\hline Ni-63 & $4.26 \mathrm{E}-01$ & $5.04 \mathrm{E}-01$ & $4.64 \mathrm{E}-01$ & $8.45 \mathrm{E}-01$ \\
\hline Np-237 & $1.01 \mathrm{E}-02$ & $5.11 \mathrm{E}-03$ & $7.64 \mathrm{E}-03$ & $2.14 \mathrm{E}-02$ \\
\hline $\mathrm{Pu}-238$ & $3.36 \mathrm{E}+00$ & $4.06 \mathrm{E}+00$ & $3.70 \mathrm{E}+00$ & $5.94 \mathrm{E}+00$ \\
\hline $\mathrm{Pu}-239$ & $8.64 \mathrm{E}+00$ & $6.41 \mathrm{E}+00$ & $7.54 \mathrm{E}+00$ & $1.62 \mathrm{E}+01$ \\
\hline $\mathrm{Pu}-239 / \mathrm{Pu}-240$ & $8.64 \mathrm{E}+00$ & $1.19 \mathrm{E}+01$ & $1.02 \mathrm{E}+01$ & $2.01 \mathrm{E}+01$ \\
\hline $\mathrm{Pu}-240$ & $1.26 \mathrm{E}+00$ & $1.40 \mathrm{E}+00$ & $1.33 \mathrm{E}+00$ & $3.27 \mathrm{E}+00$ \\
\hline $\mathrm{Pu}-241$ & $8.31 \mathrm{E}+00$ & $4.50 \mathrm{E}+00$ & $6.44 \mathrm{E}+00$ & $1.70 \mathrm{E}+01$ \\
\hline $\mathrm{Pu}-242$ & $3.09 \mathrm{E}-04$ & $3.12 \mathrm{E}-04$ & $3.11 \mathrm{E}-04$ & $1.23 \mathrm{E}-03$ \\
\hline Sb-126 & $3.75 \mathrm{E}-04$ & $3.80 \mathrm{E}-04$ & $3.77 \mathrm{E}-04$ & $5.31 \mathrm{E}-04$ \\
\hline Sb-126m & $3.75 \mathrm{E}-04$ & $3.80 \mathrm{E}-04$ & $3.77 \mathrm{E}-04$ & $5.31 \mathrm{E}-04$ \\
\hline Sm-151 & $2.62 \mathrm{E}+00$ & $1.15 \mathrm{E}+00$ & $1.89 \mathrm{E}+00$ & $6.97 \mathrm{E}+00$ \\
\hline Sn-126 & $3.75 \mathrm{E}-04$ & $3.80 \mathrm{E}-04$ & $3.77 \mathrm{E}-04$ & $5.31 \mathrm{E}-04$ \\
\hline Sr-90 & $4.78 \mathrm{E}+01$ & $4.12 \mathrm{E}+01$ & $4.46 \mathrm{E}+01$ & $8.29 \mathrm{E}+01$ \\
\hline Tc-99 & $4.31 \mathrm{E}-02$ & $4.03 \mathrm{E}-02$ & $4.18 \mathrm{E}-02$ & $5.71 \mathrm{E}-02$ \\
\hline Th-232 & $1.69 \mathrm{E}-05$ & $1.14 \mathrm{E}-06$ & & \\
\hline U-232 & $5.08 \mathrm{E}-05$ & $1.64 \mathrm{E}-04$ & $1.06 \mathrm{E}-04$ & $1.87 \mathrm{E}-04$ \\
\hline U-233 & $9.60 \mathrm{E}-04$ & $2.56 \mathrm{E}-04$ & $6.14 \mathrm{E}-04$ & $2.68 \mathrm{E}-03$ \\
\hline U-234 & $6.22 \mathrm{E}-03$ & $1.91 \mathrm{E}-3$ & $4.10 \mathrm{E}-03$ & $16.3 \mathrm{E}-03$ \\
\hline U-235 & $2.49 \mathrm{E}-04$ & $9.40 \mathrm{E}-05$ & $1.73 \mathrm{E}-04$ & $6.11 \mathrm{E}-04$ \\
\hline U-236 & $2.50 \mathrm{E}-04$ & $1.55 \mathrm{E}-04$ & $2.04 \mathrm{E}-04$ & $6.15 \mathrm{E}-04$ \\
\hline U-238 & $6.30 \mathrm{E}-03$ & $2.38 \mathrm{E}-03$ & $4.37 \mathrm{E}-03$ & $1.55 \mathrm{E}-02$ \\
\hline $\mathrm{Y}-90$ & $4.78 \mathrm{E}+01$ & $4.12 \mathrm{E}+01$ & $4.46 \mathrm{E}+01$ & $8.29 \mathrm{E}+01$ \\
\hline
\end{tabular}

${ }^{3}$ The units of measure for concentration match those reported by SRNL in Oji [2009]. If the sample was prepared "wet", then the denominator unit of measure is "wet" grams, and if the sample was prepared "dry", then the denominator units of measure are "dry" grams. 
Table 2. Chemicals Concentrations and $U C L L_{95 \%}(w t \%)$ for the Baseline Sample Plan (No Additional Sampling)

\begin{tabular}{|l|c|c|c|c|}
\hline Chemical & $\begin{array}{c}\text { Mean Concentration } \\
\text { of North Hemisphere } \\
\text { Samples }\end{array}$ & $\begin{array}{c}\text { Concentration of } \\
\text { South Hemisphere } \\
\text { Sample }\end{array}$ & $\begin{array}{c}\text { Estimated Tank } \\
\text { Concentration }\end{array}$ & $\begin{array}{c}\text { UCL } \text { 95\% }_{\text {for }} \\
\text { Concentration }\end{array}$ \\
\hline $\mathrm{Ag}$ & $5.75 \mathrm{E}-02$ & $5.89 \mathrm{E}-02$ & $5.82 \mathrm{E}-02$ & $1.28 \mathrm{E}-01$ \\
\hline $\mathrm{Al}$ & $1.37 \mathrm{E}+01$ & $1.65 \mathrm{E}+01$ & $1.51 \mathrm{E}+01$ & $2.55 \mathrm{E}+01$ \\
\hline $\mathrm{Ba}$ & $1.92 \mathrm{E}-02$ & $2.76 \mathrm{E}-02$ & $2.33 \mathrm{E}-02$ & $5.16 \mathrm{E}-02$ \\
\hline $\mathrm{C}_{2} \mathrm{O}_{4}{ }^{-2}$ & $3.31 \mathrm{E}+01$ & $3.95 \mathrm{E}+01$ & $3.62 \mathrm{E}+01$ & $5.71 \mathrm{E}+01$ \\
\hline $\mathrm{Ca}$ & $2.85 \mathrm{E}+00$ & $3.49 \mathrm{E}+00$ & $3.16 \mathrm{E}+00$ & $5.65 \mathrm{E}+00$ \\
\hline $\mathrm{Cd}$ & $7.53 \mathrm{E}-01$ & $6.40 \mathrm{E}-01$ & $6.97 \mathrm{E}-01$ & $1.21 \mathrm{E}+00$ \\
\hline $\mathrm{Cl}^{-1}$ & $5.96 \mathrm{E}+01$ & $6.57 \mathrm{E}+01$ & $6.26 \mathrm{E}+01$ & $8.52 \mathrm{E}+01$ \\
\hline $\mathrm{Co}$ & $1.42 \mathrm{E}-02$ & $8.92 \mathrm{E}-03$ & $1.16 \mathrm{E}-02$ & $3.08 \mathrm{E}-02$ \\
\hline $\mathrm{Co}{ }^{-2}$ & $3.73 \mathrm{E}+03$ & $7.78 \mathrm{E}+01$ & $1.94 \mathrm{E}+03$ & $1.82 \mathrm{E}+04$ \\
\hline $\mathrm{Cr}$ & $5.98 \mathrm{E}-02$ & $6.04 \mathrm{E}-02$ & $6.01 \mathrm{E}-02$ & $7.58 \mathrm{E}-02$ \\
\hline $\mathrm{Cu}$ & $4.28 \mathrm{E}-02$ & $9.29 \mathrm{E}-03$ & $2.63 \mathrm{E}-02$ & $7.88 \mathrm{E}-02$ \\
\hline $\mathrm{F}-1$ & $2.74 \mathrm{E}+01$ & $3.13 \mathrm{E}+01$ & $2.94 \mathrm{E}+01$ & $4.29 \mathrm{E}+01$ \\
\hline $\mathrm{Fe}$ & $7.03 \mathrm{E}+00$ & $6.44 \mathrm{E}+00$ & $6.74 \mathrm{E}+00$ & $1.11 \mathrm{E}+01$ \\
\hline $\mathrm{Hg}$ & $1.30 \mathrm{E}-01$ & $3.97 \mathrm{E}-02$ & $8.53 \mathrm{E}-02$ & $4.23 \mathrm{E}-01$ \\
\hline $\mathrm{Mg}$ & $1.32 \mathrm{E}+00$ & $1.37 \mathrm{E}+00$ & $1.34 \mathrm{E}+00$ & $3.22 \mathrm{E}+00$ \\
\hline $\mathrm{Mn}$ & $1.22 \mathrm{E}+00$ & $1.29 \mathrm{E}+00$ & $1.25 \mathrm{E}+00$ & $1.73 \mathrm{E}+00$ \\
\hline $\mathrm{Na}$ & $4.63 \mathrm{E}+00$ & $4.33 \mathrm{E}+00$ & $4.48 \mathrm{E}+00$ & $7.07 \mathrm{E}+00$ \\
\hline $\mathrm{Ni}^{-2}$ & $9.18 \mathrm{E}-02$ & $9.49 \mathrm{E}-02$ & $9.33 \mathrm{E}-02$ & $1.07 \mathrm{E}-01$ \\
\hline $\mathrm{NO}_{2}{ }^{-{ }^{*}}$ & $4.13 \mathrm{E}+01$ & $4.51 \mathrm{E}+01$ & $4.32 \mathrm{E}+01$ & $5.80 \mathrm{E}+01$ \\
\hline $\mathrm{NO}_{3}{ }^{-{ }^{*}}$ & $2.57 \mathrm{E}+02$ & $2.96 \mathrm{E}+02$ & $2.76 \mathrm{E}+02$ & $4.13 \mathrm{E}+02$ \\
\hline $\mathrm{P}$ & $1.26 \mathrm{E}-01$ & $1.34 \mathrm{E}-01$ & $1.30 \mathrm{E}-01$ & $1.64 \mathrm{E}-01$ \\
\hline $\mathrm{Pb}$ & $6.69 \mathrm{E}-02$ & $4.01 \mathrm{E}-02$ & $5.37 \mathrm{E}-02$ & $1.46 \mathrm{E}-01$ \\
\hline $\mathrm{Si}$ & $3.79 \mathrm{E}+00$ & $9.15 \mathrm{E}+00$ & $6.43 \mathrm{E}+00$ & $2.46 \mathrm{E}+01$ \\
\hline $\mathrm{Sn}$ & $3.55 \mathrm{E}-02$ & $7.81 \mathrm{E}-03$ & $2.19 \mathrm{E}-02$ & $1.39 \mathrm{E}-01$ \\
\hline $\mathrm{SO}{ }_{4}{ }^{-2}$ & $3.95 \mathrm{E}+01$ & $4.22 \mathrm{E}+01$ & $4.08 \mathrm{E}+01$ & $5.23 \mathrm{E}+01$ \\
\hline $\mathrm{Sr}$ & $1.18 \mathrm{E}-02$ & $1.48 \mathrm{E}-02$ & $1.33 \mathrm{E}-02$ & $2.53 \mathrm{E}-02$ \\
\hline $\mathrm{Ti}$ & $1.30 \mathrm{E}-02$ & $1.78 \mathrm{E}-02$ & $1.54 \mathrm{E}-02$ & $3.70 \mathrm{E}-02$ \\
\hline $\mathrm{U}$ & $1.20 \mathrm{E}+00$ & $1.34 \mathrm{E}+00$ & $1.27 \mathrm{E}+00$ & $2.02 \mathrm{E}+00$ \\
\hline $\mathrm{Zn}$ & $1.97 \mathrm{E}-02$ & $2.26 \mathrm{E}-02$ & $2.11 \mathrm{E}-02$ & $3.12 \mathrm{E}-02$ \\
\hline $\mathrm{Zr}$ & $4.48 \mathrm{E}-03$ & $7.01 \mathrm{E}-03$ & $5.72 \mathrm{E}-03$ & $1.40 \mathrm{E}-02$ \\
\hline & & & & \\
\hline
\end{tabular}

units are $\mu \mathrm{g} / \mathrm{g}$

The baseline sample plan refers to the current status of having one Mantis sample in each hemisphere and a QA floor scrape sample in the North hemisphere; no additional sampling was assumed for the baseline sampling plan. The $U C L_{95 \%}$ in the table applies to the baseline sample plan. The $U C L_{95 \%}$ for an analyte $a$ is the upper $95 \%$ confidence limit for the actual mean tank concentration, $A$, for analyte $a$. The $95 \%$ level of confidence refers to the reliability of the method, in that $95 \%$ of such upper confidence values will correctly bound the actual mean concentration of an analyte $a$. 
Th-232 was a special case since it had no reported $U C L_{95 \%}$. All six Th-232 determinations on the North Mantis sample were below detection; the highest detection limit was reported as the North hemisphere concentration mean. Four of the six Th-232 determinations on the South Mantis sample were below detection, and two of the six Th-232 determinations resulted in reported measurements. Both measured values had lower concentrations than the four detection limits. The average of the two measurements was reported for the South hemisphere.

Analogous to Table 1, Table 2 lists all non-radioactive chemicals that have sufficient measurements from the Huff and Thaxton [2009] sampling plan to compute an $U C L_{95 \%}$. Again, the $U C L_{95 \%}$ refers to the baseline sampling plan with no additional sampling. Nonradioactive chemical concentrations are reported in $\mathrm{wt} \%$.

Table 4 in the appendix lists all constituents, radionuclides and chemicals, on which every concentration measurement was reported as less than detection. Appendix Table 5 and Table 6 are a complete accounting of every radionuclide and chemical, respectively, reported in Oji [2009], along with a description of the data: all measurements (above detection limits), all measurements reported as less than detection, or a mix of the two. It also contains a column reporting whether the analysis was conducted on a "wet" or a "dry" sample.

Besides the baseline sampling plan, addition sampling plans were considered with 1, 2, 3, 4,5 , and 10 additional samples in each hemisphere. In each of these plans, the number of analyses on each of the added samples was assumed to be three since additional measurements were shown to provide very little reduction in the UCL $95 \%$. The relative $U C L_{95 \%}$ from formula (3) was computed for each analyte under each of these sampling scenarios. This measures the total range of uncertainty in an analyte's concentration that lies above the estimated concentration relative to the estimated concentration. If the sample size had been extremely large, the relative $U C L_{95 \%}$ would decrease to near zero.

The analytes were divided into subsets depending on the size of the relative $U C L_{95 \%}$ for the case of 1 additional sample per hemisphere. The group with a relative $U C L_{95 \%}$ up to $25 \%$ is shown in appendix Figure 4 . The plot shows the relative $U C L_{95 \%}$ decreasing as the number of additional samples increases. The large drop between 1 and 2 additional samples per hemisphere is followed by a series of much smaller decreases in the relative $U C L_{95 \%}$.

Appendix Figure 5 through Figure 8 display the results for analytes with a relative $U C L_{95 \%}$ between 26 and $50 \%, 51$ to $75 \%, 76$ to $100 \%$, and greater than $100 \%$, respectively. All plots exhibit the same characteristic, with the drops in the relative $U C L_{95 \%}$ decreasing after 5 additional samples.

It should be noted that the sampling variance in many cases was computed from the difference between the North and South Mantis sample concentration means. This difference could be large simply because the actual concentration of an analyte was very different between the two hemispheres. Figure 8 captures the largest relative $U C L_{95 \%}$ 
values, and may be dominated by actual hemisphere concentration differences using in the planning, rather than the intended sampling error variation or within hemisphere differences.

\subsection{The Number of Additional Samples}

The final sample size is determined when the reduction in uncertainty from an additional sample no longer has a practical impact on the results. Assume the baseline sample plan, one Mantis sample in each hemisphere and one North floor scrape sample, can be used as a starting point. The plot in Appendix Figure 3 displays the decrease in uncertainty as more and more additional samples are obtained. Figure 4 pertains to just the analytes which have relative uncertainties no greater than $25 \%$. The decrease becomes smaller and smaller as more samples are added. Five additional samples were selected as a point of diminishing returns. In addition to the five samples, two more samples will be obtained and archived, bringing the final number of additional samples to seven. If the Mantis samples cannot be demonstrated to be comparable to the floor scrape samples, then the two archived samples will be analyzed. Appendix Figure 5 though Figure 8 have similar patterns of uncertainty reduction, so the same result is obtained. Comparing the uncertainty associated with five additional samples to the uncertainty with 19 additional samples (the latter representing an intensively sampled scenario) in these figures, the reader can confirm that more than half of the reduction in uncertainty is already achieved with just five additional samples.

\subsection{SAMPLE PLACEMENT}

The recommendations that follow are based on three observations. First, if Mantis samples are to be used, they must be demonstrated to have similar characteristics to floor scrape samples, that is, the Mantis sampling procedure should not have altered the concentration of analytes in the solids. If shown to be comparable, the previously obtained Mantis rover and floor scrape sample information can all be used to support the quantification of analytes in the residual material. Otherwise, the Mantis samples should not be used in final concentration estimates, and an additional sample should be obtained and archived as a contingency for each Mantis sample.

Second, previous work has assumed that analyte concentrations may differ between the North and South hemispheres, and so each hemisphere should be sampled independently. Then, only after a comparison of samples in the two hemispheres demonstrates similarities relative to sampling variation, should the results from the entire tank be consolidated into a single unit. If the results from the North and the South hemispheres cannot be demonstrated to be similar, then the sampling plan must support separate quantification of the analyte concentrations in the two hemispheres.

Third, the existing North sample, obtained from the floor area northwest of the Center 
Riser, was obtained from a single compact ${ }^{4}$ region. The previous South Mantis sample has been consolidated from three locations, but with two-thirds of the material having come from a single location, it is expected to reflect the location from which most of its solids were obtained. Therefore, none of the samples obtained up to this point in time should be considered true spatially-distributed averages of separate locations, and the additional sample(s) should be obtained from similar compact regions, and not composited from discrete disconnected regions.

A Mantis rover sample that was obtained near the West Riser has been archived and is available for use. A tank floor diagram for Tank 18 is depicted in Figure 2 of the appendix that shows the locations of the previous samples obtained by the Mantis. This diagram shows that the material previously obtained near the West riser represents an area of the tank that has not been evaluated to date.

The following recommendations may be subject to physical tank access and sampling constraints affecting the placement of additional samples. Partition the Tank 18 floor into an inner and an outer ring and six $60^{\circ}$ sectors as depicted in Figure 1. The location of the border between the inner and outer rings is based on dividing the residual material into two approximately equal volumes. There will be a total of four samples from each hemisphere including the new samples to be archived once the additional sampling has been completed. In order to balance the samples between the inner and outer rings (two samples in each ring per hemisphere), one additional sample should be taken from the outer ring in the North hemisphere and two additional samples should be taken from the outer ring in the South hemisphere. The material in the southwest outer ring should be sampled because the material in this region was shown to differ from the other material in the tank prior to the Mantis cleaning (2005 - Thomas). One additional sample to be analyzed should be obtained from the inner ring of each hemisphere. The two additional samples slated to be archived should also be taken from the inner ring, since they are the primary contingency if the Mantis samples (from the inner ring) are demonstrated to be incompatible with the other sample results. One of the archived samples should be taken in each hemisphere. The choice of $60^{\circ}$ sector for archived samples should be made so at least one sample to be analyzed is located in each sector regardless of whether the Mantis samples are used.

\footnotetext{
4 A compact region, as used in this report, refers to a contiguous area from which the material for a sample has been obtained.
} 


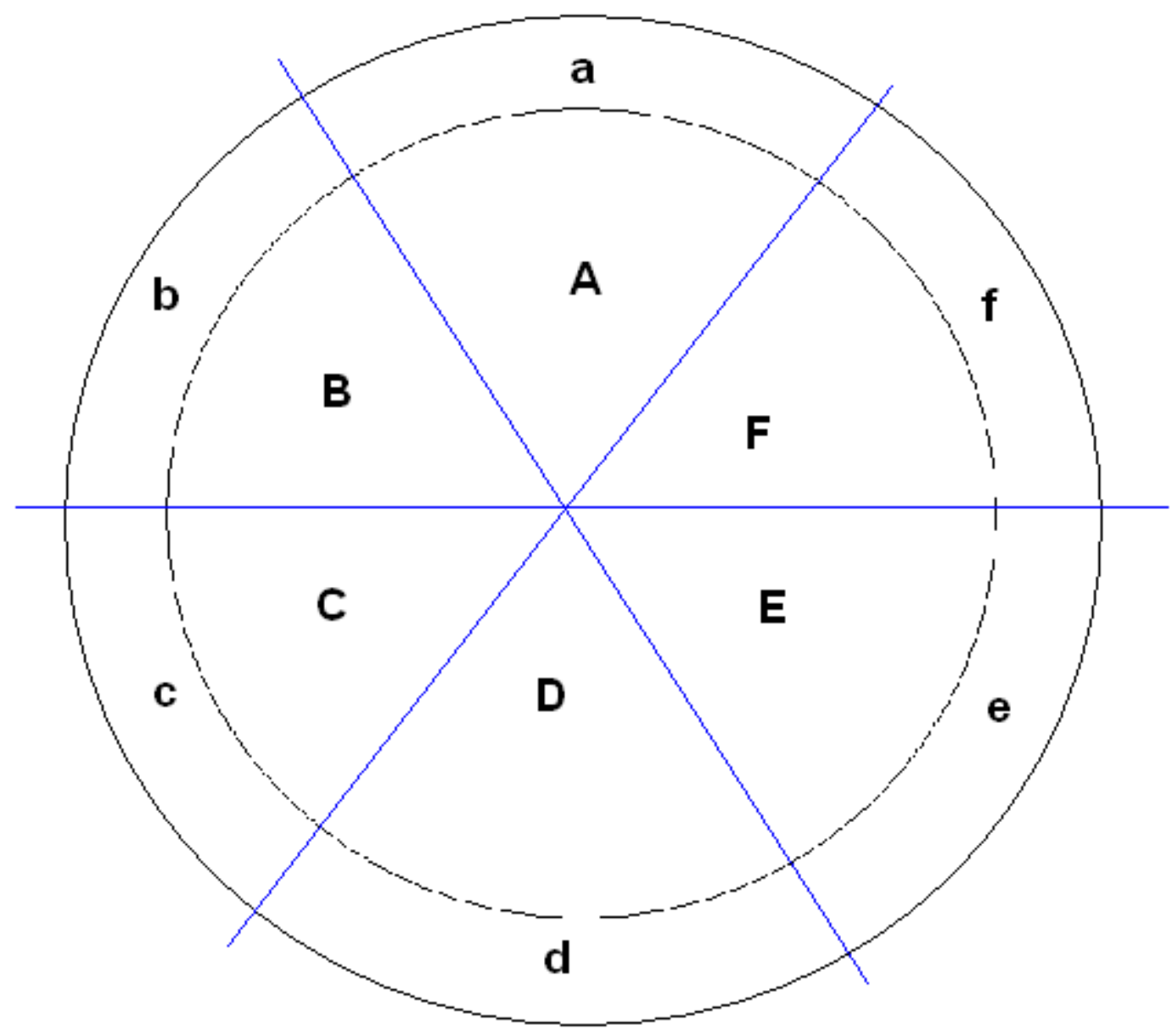

Figure 1. Layout for additional sampling locations in Tank 18

\subsection{RESULTS AND CONCLUSIONS}

The characterization of the full suite of analytes in the North hemisphere is currently supported by a single Mantis rover sample obtained from a compact region near the center riser. A floor scrape sample was obtained from a compact region near the northeast riser and has been analyzed for a shortened list of key analytes. Since the unused portion of the floor scrape sample material is archived and available in sufficient quantity, additional analyses need to be performed to complete results for the full suite of constituents. The characterization of the full suite of analytes in the South hemisphere is currently supported by a single Mantis rover sample; there have been no floor scrape samples previously taken from the South hemisphere.

The criterion to determine the number of additional samples was based on the practical reduction in the uncertainty when a new sample is added. This was achieved when five additional samples are obtained. In addition, two archived samples will be used if a 
contingency such as failing to demonstrate the comparability of the Mantis samples to the floor scrape samples occurs.

To complete sampling of the Tank 18 residual floor material, three additional samples should be taken from the North hemisphere and four additional samples should be taken from the South hemisphere. One of the samples from each hemisphere will be archived in case of need. Two of the three additional samples from the North hemisphere and three of the four additional samples from the South hemisphere will be analyzed. Once the results are available, differences between the Mantis and three floor scrape samples (the sample previously obtained near NE riser plus the two additional samples that will be analyzed) results will be evaluated. If there are no statistically significant analyte concentration differences between the Mantis and floor scrape samples, those results will be combined and then $U C L_{95 \%} \mathrm{~s}$ will be calculated. If the analyte concentration differences between the Mantis and floor scrape samples are statistically significant, the $U C L_{95 \%} \mathrm{~s}$ will be calculated without the Mantis sample results. If further reduction in the upper confidence limits is needed and can be achieved by the addition of the archived samples, they will be analyzed and included in the statistical computations.

Initially, the analyte concentrations in the residual material on the floor of Tank 18 will be determined separately in the North and the South hemispheres. However, if final sampling results show that differences between the North and South samples are consistent within sampling variation, then the final computations can be based on consolidating all sample results from the tank floor.

Recommended locations may be subject to physical tank access and sampling constraints for the additional samples. The recommendations have been discussed in Section 4 and are based on partitioning the Tank 18 floor into an inner and an outer ring and six $60^{\circ}$ sectors depicted in Figure 1. The location of the border between the inner and outer rings is based on dividing the residual material into two approximately equal volumes. Apart from the new samples to be archived, there will be four floor samples (Mantis and scrape) from each hemisphere once the additional sampling has been completed. In order to balance the samples between the inner and outer rings (two samples in each ring per hemisphere), one additional sample should be taken from the outer ring in the North hemisphere and two additional samples should be taken from the outer ring in the South hemisphere. One additional sample to be analyzed should be obtained from the inner ring of each hemisphere. The two additional samples slated to be archived (1 from each hemisphere) should also be obtained from the inner ring, since they are the primary contingency if the Mantis samples (from the inner ring) are demonstrated to be incompatible with the other sample results. 


\subsection{REFERENCES}

[2009] Barbour, K. Drawing of Previous Sample Locations and Available Entry Locations, personal e-mail communication.

[2001] Edwards, T.B., "A Decision Support Tool for Planning the Sampling of Tank 19 (U),” WSRC-RP-2001-00781, Revision 0, July 2001.

[2008] Edwards, T.B. and Shine, E.P. "Preliminary Statistical Support for Sampling Tanks 5 and 6", Draft SRNL-L5100-2008-00007, Savannah River Site, Aiken, SC. (October 22).

[2009] Huff, T. and Thaxton, G.D. Draft of "Tanks 18 and 19 Waste Determination Sample Plan," LWO-LWE-2008-00186, Revision 2, Savannah River Site, Aiken, SC. (June 22).

[2009] Ludwig, W. "Waste Tanks 18 \& 19 Maps and Volumes," e-mail communication to E.P. Shine (November 22).

[2005] Thomas, J.L. "Characterization of Tank 18 Residual Waste," Technical Report UTR-F-00005, Rev. 2, Savannah River Site, (August). 


\subsection{APPENDIX}

Table 3. Sample Information from the Mantis Rover Samples ${ }^{1}$

\begin{tabular}{|c|c|c|c|c|c|c|c|c|}
\hline $\begin{array}{c}\text { Sample } \\
\text { Site } \\
\end{array}$ & $\begin{array}{l}\text { Quadrant } \\
\text { Sampled }\end{array}$ & Hemisphere & $\begin{array}{l}\text { Direction from } \\
\text { Closest Riser }\end{array}$ & Est. wt.g & Total wt., g & $\begin{array}{c}\text { Date } \\
\text { Sampled }\end{array}$ & $\begin{array}{l}\text { Received } \\
\text { a SRNL }\end{array}$ & Comments \\
\hline 1 & FTF-07-09-09-1 & North & SW of the NE Riser & 1 & 3.5 & $1 / 31 / 2009$ & 2/3/2009 & Sample Archived \\
\hline 1 & FTF-07-09-09-2 & North & SW of the NE Riser & 0.5 & 3.5 & $1 / 31 / 2009$ & $2 / 3 / 2009$ & Sample Archived \\
\hline 1 & FTF-07-09-09-3 & North & SW of the NE Riser & 2 & 3.5 & $1 / 31 / 2009$ & $2 / 3 / 2009$ & Sample Archived \\
\hline 2 & FTF-07-09-10-1 & North & East of Center Riser & 1 & 3.5 & $1 / 31 / 2009$ & $2 / 3 / 2009$ & Sample Archived \\
\hline 2 & FTF-07-09-10-2 & North & East of Center Riser & 2 & 3.5 & $1 / 31 / 2009$ & $2 / 3 / 2009$ & Sample Archived \\
\hline 2 & FTF-07-09-10-3 & North & East of Center Riser & 0.5 & 3.5 & $1 / 31 / 2009$ & $2 / 3 / 2009$ & Sample Archived \\
\hline 3 & FTF-07-09-18-1 & South $^{2}$ & South of West Riser & 1 & 15.5 & $2 / 28 / 2009$ & $3 / 2 / 2009$ & Sample Archived \\
\hline 3 & FTF-07-09-18-2 & South & South of West Riser & 1 & 15.5 & $2 / 28 / 2009$ & $3 / 2 / 2009$ & Sample Archived \\
\hline 3 & FTF-07-09-18-3 & South & South of West Riser & 0.5 & 15.5 & $2 / 28 / 2009$ & $3 / 2 / 2009$ & Sample Archived \\
\hline 3 & FTF-07-09-18-4 & South & South of West Riser & 1 & 15.5 & $2 / 28 / 2009$ & $3 / 2 / 2009$ & Sample Archived \\
\hline 3 & FTF-07-09-18-5 & South & South of West Riser & 0.5 & 15.5 & $2 / 28 / 2009$ & $3 / 2 / 2009$ & Sample Archived \\
\hline 3 & FTF-07-09-18-6 & South & South of West Riser & 0.5 & 15.5 & $2 / 28 / 2009$ & $3 / 2 / 2009$ & Sample Archived \\
\hline 3 & FTF-07-09-18-7 & South & South of West Riser & 2 & 15.5 & $2 / 28 / 2009$ & $3 / 2 / 2009$ & Sample Archived \\
\hline 3 & FTF-07-09-18-8 & South & South of West Riser & 2 & 15.5 & $2 / 28 / 2009$ & $3 / 2 / 2009$ & Sample Archived \\
\hline 3 & FTF-07-09-18-9 & South & South of West Riser & 1 & 15.5 & $2 / 28 / 2009$ & $3 / 2 / 2009$ & Sample Archived \\
\hline 3 & FTF-07-09-18-10 & South & South of West Riser & 0.5 & 15.5 & $2 / 28 / 2009$ & $3 / 2 / 2009$ & Sample Archived \\
\hline 3 & FTF-07-09-18-11 & South & South of West Riser & 1 & 15.5 & $2 / 28 / 2009$ & $3 / 2 / 2009$ & Sample Archived \\
\hline 3 & FTF-07-09-18-12 & South & South of West Riser & 0.5 & 15.5 & $2 / 28 / 2009$ & $3 / 2 / 2009$ & Sample Archived \\
\hline 3 & FTF-07-09-18-13 & South & South of West Riser & 1 & 15.5 & $2 / 28 / 2009$ & $3 / 2 / 2009$ & Sample Archived \\
\hline 3 & FTF-07-09-18-14 & South & South of West Riser & 2 & 15.5 & $2 / 28 / 2009$ & $3 / 2 / 2009$ & Sample Archived \\
\hline 3 & FTF-07-09-18-15 & South & South of West Riser & 1 & 15.5 & $2 / 28 / 2009$ & $3 / 2 / 2009$ & Sample Archived \\
\hline
\end{tabular}

1 Table information from E-mail communication from Type IV Tank Closure org. August 10, 2009

2 This sample was originally labeled as coming from the North hemisphere. Video of the sampling indicated that the sample was actually obtained in the South hemisphere. It is labeled in red. 


\begin{tabular}{|c|c|c|c|c|c|c|c|c|}
\hline $\begin{array}{c}\text { Sample } \\
\text { Site }\end{array}$ & $\begin{array}{l}\text { Quadrant } \\
\text { Sampled }\end{array}$ & Hemisphere & $\begin{array}{l}\text { Direction from } \\
\text { Closest Riser }\end{array}$ & Est. wt.g & Total wt., g & $\begin{array}{c}\text { Date } \\
\text { Sampled }\end{array}$ & $\begin{array}{l}\text { Received } \\
\text { a SRNL }\end{array}$ & Comments \\
\hline 4 & FTF-07-09-20-2 & North & NW of Center Riser & 2 & 40 & $3 / 9 / 2009$ & $3 / 16 / 2009$ & Sample Composited \\
\hline 4 & FTF-07-09-20-4 & North & NW of Center Riser & 3 & 40 & $3 / 9 / 2009$ & $3 / 16 / 2009$ & Sample Composited \\
\hline 4 & FTF-07-09-20-5 & North & NW of Center Riser & 1 & 40 & 3/9/2009 & $3 / 16 / 2009$ & Sample Composited \\
\hline 4 & FTF-07-09-20-6 & North & NW of Center Riser & 3 & 40 & $3 / 9 / 2009$ & $3 / 16 / 2009$ & Sample Composited \\
\hline 4 & FTF-07-09-20-9 & North & NW of Center Riser & 3 & 40 & 3/9/2009 & $3 / 16 / 2009$ & Sample Composited \\
\hline 4 & FTF-07-09-20-10 & North & NW of Center Riser & 0.5 & 40 & $3 / 9 / 2009$ & $3 / 16 / 2009$ & Sample Composited \\
\hline 4 & FTF-07-09-20-11 & North & NW of Center Riser & 1 & 40 & 3/9/2009 & $3 / 16 / 2009$ & Sample Composited \\
\hline 4 & FTF-07-09-20-12 & North & NW of Center Riser & 0.5 & 40 & 3/9/2009 & $3 / 16 / 2009$ & Sample Composited \\
\hline 4 & FTF-07-09-20-13 & North & NW of Center Riser & 4 & 40 & $3 / 9 / 2009$ & $3 / 16 / 2009$ & Sample Composited \\
\hline 4 & FTF-07-09-20-14 & North & NW of Center Riser & 6 & 40 & 3/9/2009 & $3 / 16 / 2009$ & Sample Composited \\
\hline $5 \mathrm{~A}$ & FTF-07-09-12-1 & South & South of Center Riser & 3 & 39 & $2 / 2 / 2009$ & $2 / 3 / 2009$ & Sample Composited \\
\hline $5 \mathrm{~A}$ & FTF-07-09-12-2 & South & South of Center Riser & 4 & 39 & $2 / 2 / 2009$ & $2 / 3 / 2009$ & Sample Composited \\
\hline $5 \mathrm{~A}$ & FTF-07-09-12-3 & South & South of Center Riser & 8 & 39 & $2 / 2 / 2009$ & $2 / 3 / 2009$ & Sample Composited \\
\hline 5B & FTF-07-09-19-1 & South & NW of SE Riser & 2 & - & $3 / 1 / 2009$ & $3 / 2 / 2009$ & Sample Archived \\
\hline $5 \mathrm{~B}$ & FTF-07-09-19-2 & South & NW of SE Riser & 1 & 39 & $3 / 1 / 2009$ & $3 / 2 / 2009$ & Sample Composited \\
\hline $5 \mathrm{~B}$ & FTF-07-09-19-3 & South & NW of SE Riser & 0 & 39 & $3 / 1 / 2009$ & $3 / 2 / 2009$ & Sample Composited \\
\hline $5 \mathrm{C}$ & FTF-07-09-21-1 & South & West of East Riser & 6 & 39 & $3 / 9 / 2009$ & $3 / 11 / 2009$ & Sample Composited \\
\hline $5 \mathrm{C}$ & FTF-07-09-21-2 & South & West of East Riser & 8 & - & $3 / 9 / 2009$ & $3 / 11 / 2009$ & Sample Archived \\
\hline $5 \mathrm{C}$ & FTF-07-09-21-3 & South & West of East Riser & 6 & 39 & $3 / 9 / 2009$ & $3 / 11 / 2009$ & Sample Composited \\
\hline
\end{tabular}

Table information from E-mail communication from Type IV Tank Closure org. August 10, 2009 
Table 4. Constituents Below Detection Limits

\begin{tabular}{|c|c|}
\hline Radionuclides & Chemicals \\
\hline Ce-144 & Ac-227 \\
\hline Cf-249 & Al-26 \\
\hline Cf-251 & As \\
\hline Cf-252 & $\mathrm{B}$ \\
\hline $\mathrm{Cm}-243$ & $\mathrm{Be}$ \\
\hline $\mathrm{Cm}-245$ & $\mathrm{Ce}$ \\
\hline $\mathrm{Cm}-247$ & $\mathrm{CHO}_{2}^{-1}$ \\
\hline $\mathrm{Cm}-248$ & $\mathrm{Gd}$ \\
\hline Cs-134 & $\mathrm{K}$ \\
\hline Eu-152 & $\mathrm{La}$ \\
\hline Gross Alpha & $\mathrm{Li}$ \\
\hline $\mathrm{H}-3$ & Mo \\
\hline I-129 & \\
\hline Na-22 & \\
\hline $\mathrm{Nb}-94$ & \\
\hline $\mathrm{Pa}-231$ & \\
\hline Pm-147 & \\
\hline Pr-144 & \\
\hline $\mathrm{Pu}-244$ & \\
\hline Ra-226 & \\
\hline Ra-228 & \\
\hline Rh-106 & \\
\hline Sb-125 & \\
\hline Se-79 & \\
\hline Te-125m & \\
\hline Th-229 & \\
\hline Th-230 & \\
\hline
\end{tabular}


SRNL-STI-2009-00782

December 14, 2009

Recommendations for Sampling of Tank 18 in F Tank Farm

Page 22

Table 5. Description of Evaluated Radionuclides

\begin{tabular}{|c|c|c|}
\hline Radionuclide & Data Description & Measurement Type \\
\hline Am-241 & All Measured & Wet \\
\hline Am-243 & All Measured & Wet \\
\hline Am-242m & Measured and Below Detection & Wet \\
\hline $\mathrm{Ba}-137 \mathrm{~m}$ & All Measured & Dry \\
\hline C-14 & All Measured & Wet \\
\hline $\mathrm{Cm}-244$ & All Measured & Wet \\
\hline Co-60 & All Measured & Wet \\
\hline $\mathrm{Cm}-242$ & Measured and Below Detection & Wet \\
\hline Cs-135 & Measured and Below Detection & Dry \\
\hline Cs-137 & All Measured & Dry \\
\hline Eu-154 & All Measured & Wet \\
\hline $\mathrm{Ni}-59$ & Measured and Below Detection & Wet \\
\hline $\mathrm{Ni}-63$ & Measured and Below Detection & Wet \\
\hline Np-237 & All Measured & Dry \\
\hline $\mathrm{Pu}-238$ & All Measured & Dry \\
\hline $\mathrm{Pu}-239$ & All Measured & Dry \\
\hline $\mathrm{Pu}-239 / \mathrm{Pu}-240$ & All Measured & Dry \\
\hline $\mathrm{Pu}-240$ & Measured and Below Detection & Dry \\
\hline $\mathrm{Pu}-242$ & Measured and Below Detection & Dry \\
\hline $\mathrm{Pu}-241$ & All Measured & Dry \\
\hline Sb-126 & All Measured & Wet \\
\hline $\mathrm{Sb}-126 \mathrm{~m}$ & All Measured & Wet \\
\hline Sm-151 & Measured and Below Detection & Dry \\
\hline Th-232 & Measured and Below Detection & Dry \\
\hline Sn-126 & All Measured & Wet \\
\hline Sr-90 & All Measured & Dry \\
\hline Tc-99 & All Measured & Wet \\
\hline $\mathrm{U}-232$ & Measured and Below Detection & Dry \\
\hline U-233 & All Measured & Dry \\
\hline U-234 & All Measured & Dry \\
\hline $\mathrm{U}-235$ & All Measured & Dry \\
\hline $\mathrm{U}-236$ & Measured and Below Detection & Dry \\
\hline U-238 & All Measured & Dry \\
\hline $\mathrm{Y}-90$ & All Measured & Dry \\
\hline
\end{tabular}


Table 6. Description of Evaluated Chemicals

\begin{tabular}{|c|c|c|}
\hline Chemical & Data Description & Measurement Type \\
\hline $\mathrm{Ag}$ & All Measured & Dry \\
\hline $\mathrm{Al}$ & All Measured & Dry \\
\hline $\mathrm{Ba}$ & All Measured & Dry \\
\hline $\mathrm{C}_{2} \mathrm{O}_{4}^{-2}$ & All Measured & Wet \\
\hline $\mathrm{Ca}$ & All Measured & Dry \\
\hline $\mathrm{Cd}$ & All Measured & Dry \\
\hline $\mathrm{Cl}^{-1}$ & All Measured & Wet \\
\hline $\mathrm{Co}$ & All Measured & Dry \\
\hline $\mathrm{Co}_{3}^{-2}$ & All Measured & Wet \\
\hline $\mathrm{Cr}$ & All Measured & Dry \\
\hline$\overline{\mathrm{Cu}}$ & Measured and Below Detection & Dry \\
\hline $\mathrm{F}^{-1}$ & All Measured & Wet \\
\hline $\mathrm{Fe}$ & All Measured & Dry \\
\hline $\mathrm{Hg}$ & All Measured & Dry \\
\hline $\mathrm{Mg}$ & All Measured & Dry \\
\hline $\mathrm{Mn}$ & All Measured & Dry \\
\hline $\mathrm{Na}$ & All Measured & Dry \\
\hline $\mathrm{Ni}$ & Measured and Below Detection & Dry \\
\hline $\mathrm{NO}_{2}{ }^{-1}$ & All Measured & Wet \\
\hline $\mathrm{NO}_{3}^{-1}$ & All Measured & Wet \\
\hline $\mathrm{P}$ & Measured and Below Detection & Dry \\
\hline $\mathrm{Pb}$ & All Measured & Dry \\
\hline $\mathrm{Si}$ & All Measured & Dry \\
\hline $\mathrm{Sn}$ & All Measured & Dry \\
\hline $\mathrm{SO}_{4}^{-2}$ & All Measured & Wet \\
\hline $\mathrm{Ti}$ & Measured and Below Detection & Dry \\
\hline $\mathrm{U}$ & Measured and Below Detection & Dry \\
\hline $\mathrm{Zn}$ & Measured and Below Detection & Dry \\
\hline $\mathrm{Sr}$ & All Measured & Dry \\
\hline $\mathrm{Zr}$ & All Measured & Dry \\
\hline
\end{tabular}




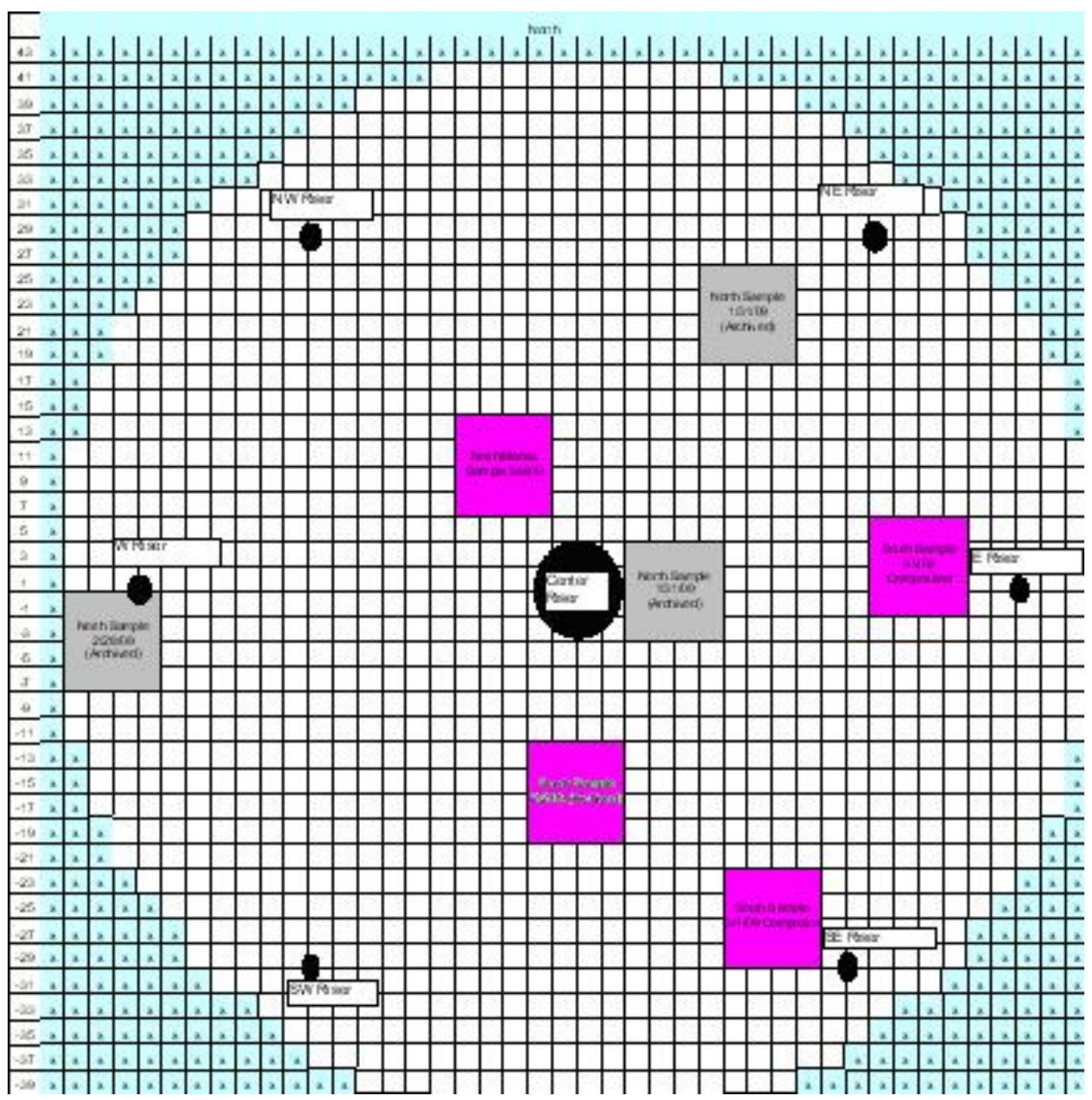

Figure 2. $\quad$ Previous $^{1}$ Mantis rover sampling locations in Tank 18 $^{2}$

${ }^{1}$ Each of squares forming the grid is 2-by-2 feet square.

2 Table information from E-mail communication from K. Barbour, Type IV Tank Closure org., August 10, 2009 


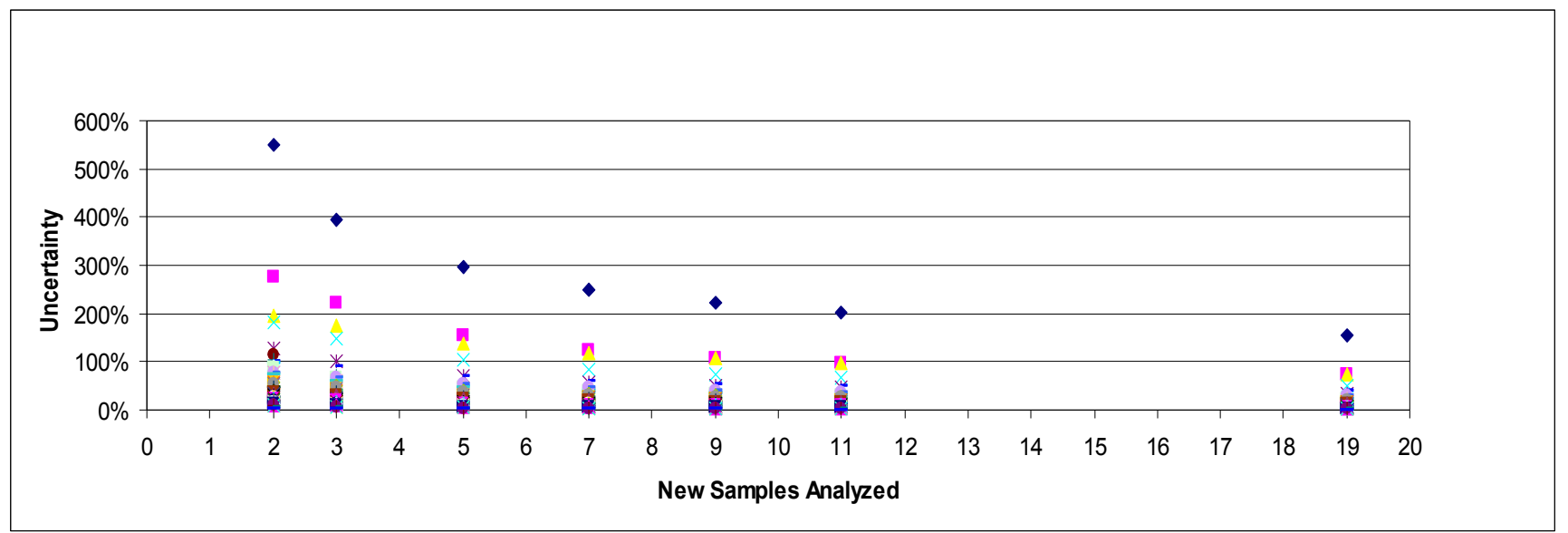

Figure 3. Uncertainty per Additional Samples (All Analytes)

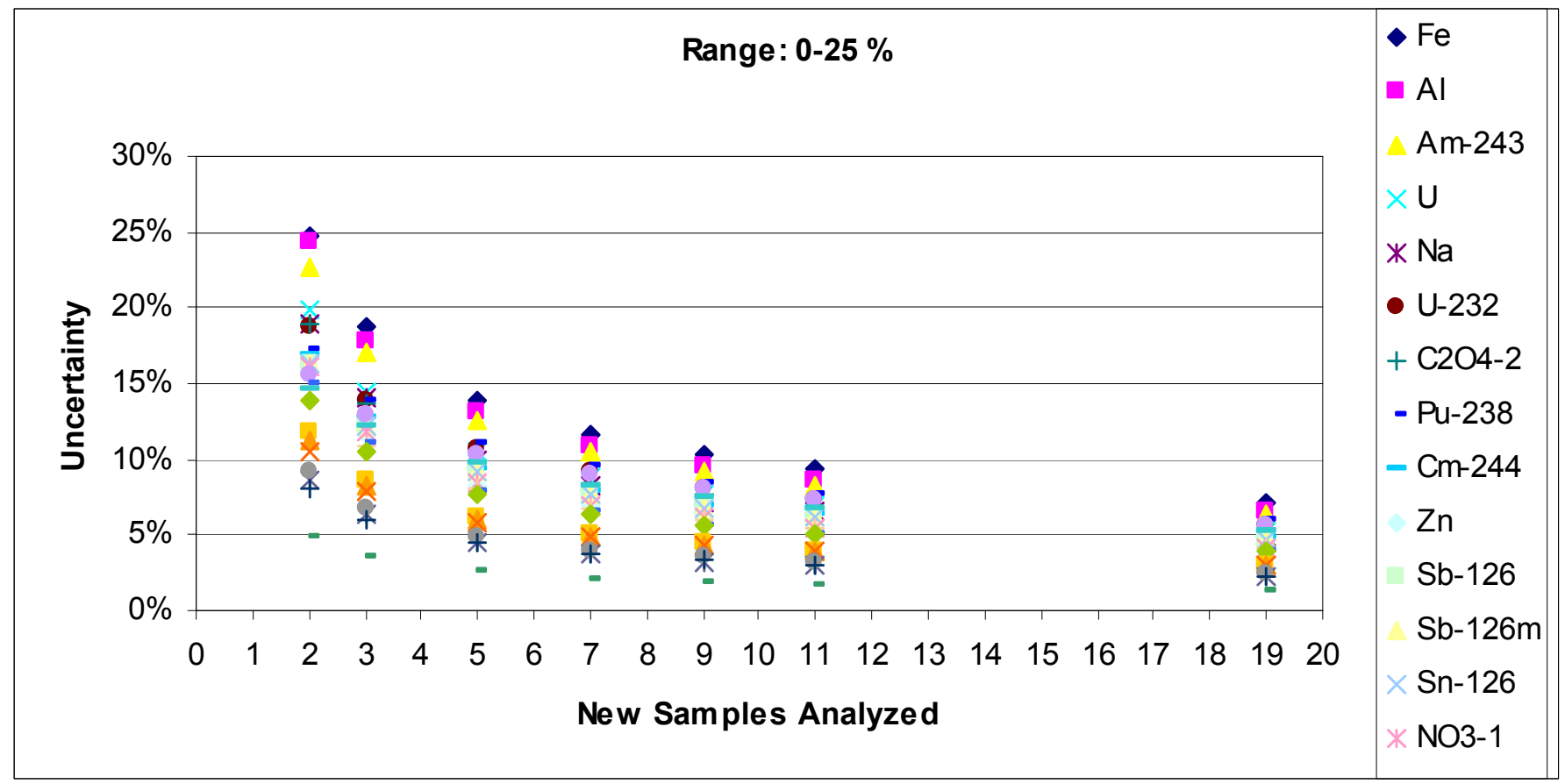

Figure 4. Uncertainty per Additional Samples (0-25\%) 


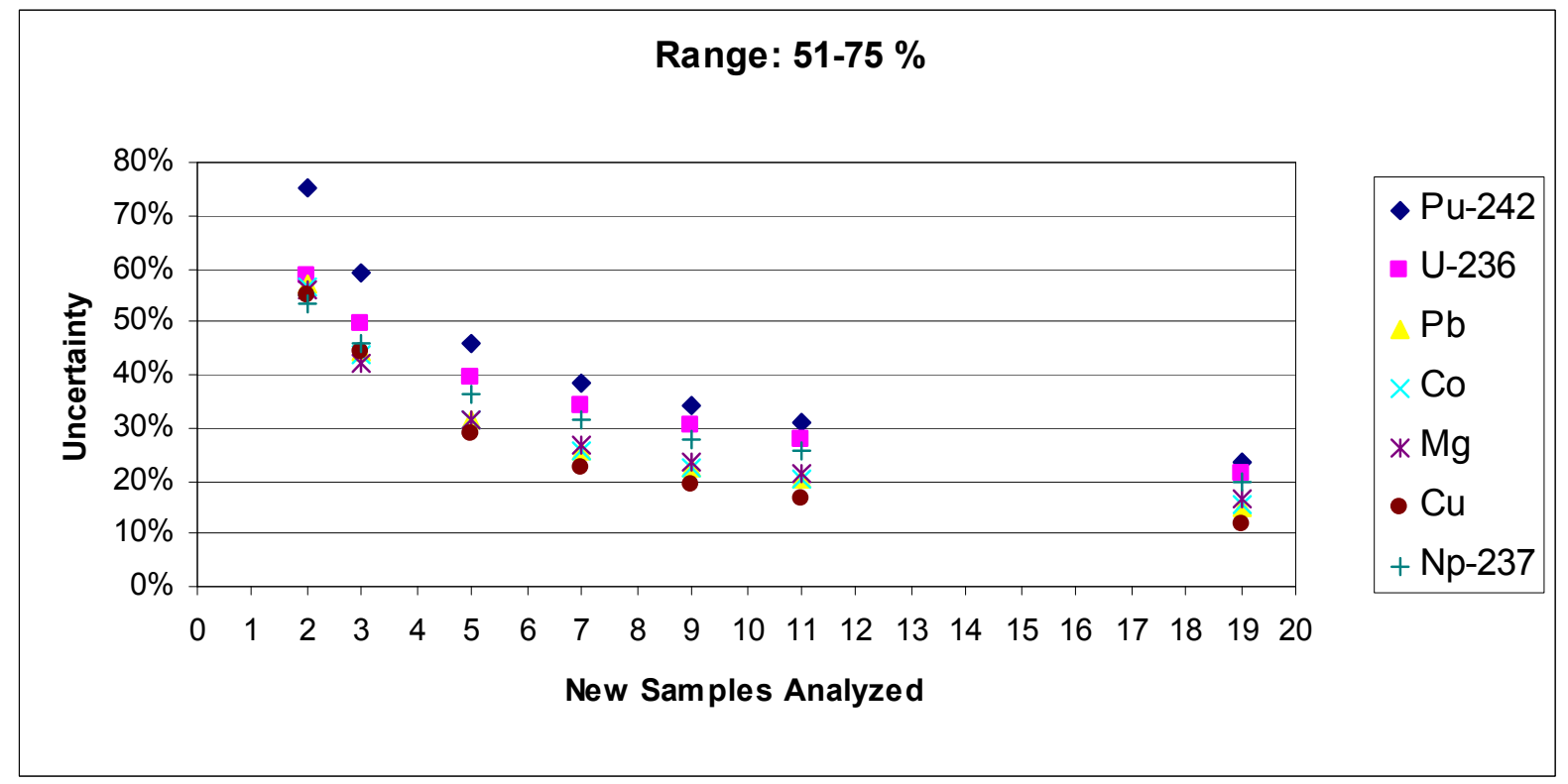

Figure 5. Uncertainty per Additional Samples (26-50\%)

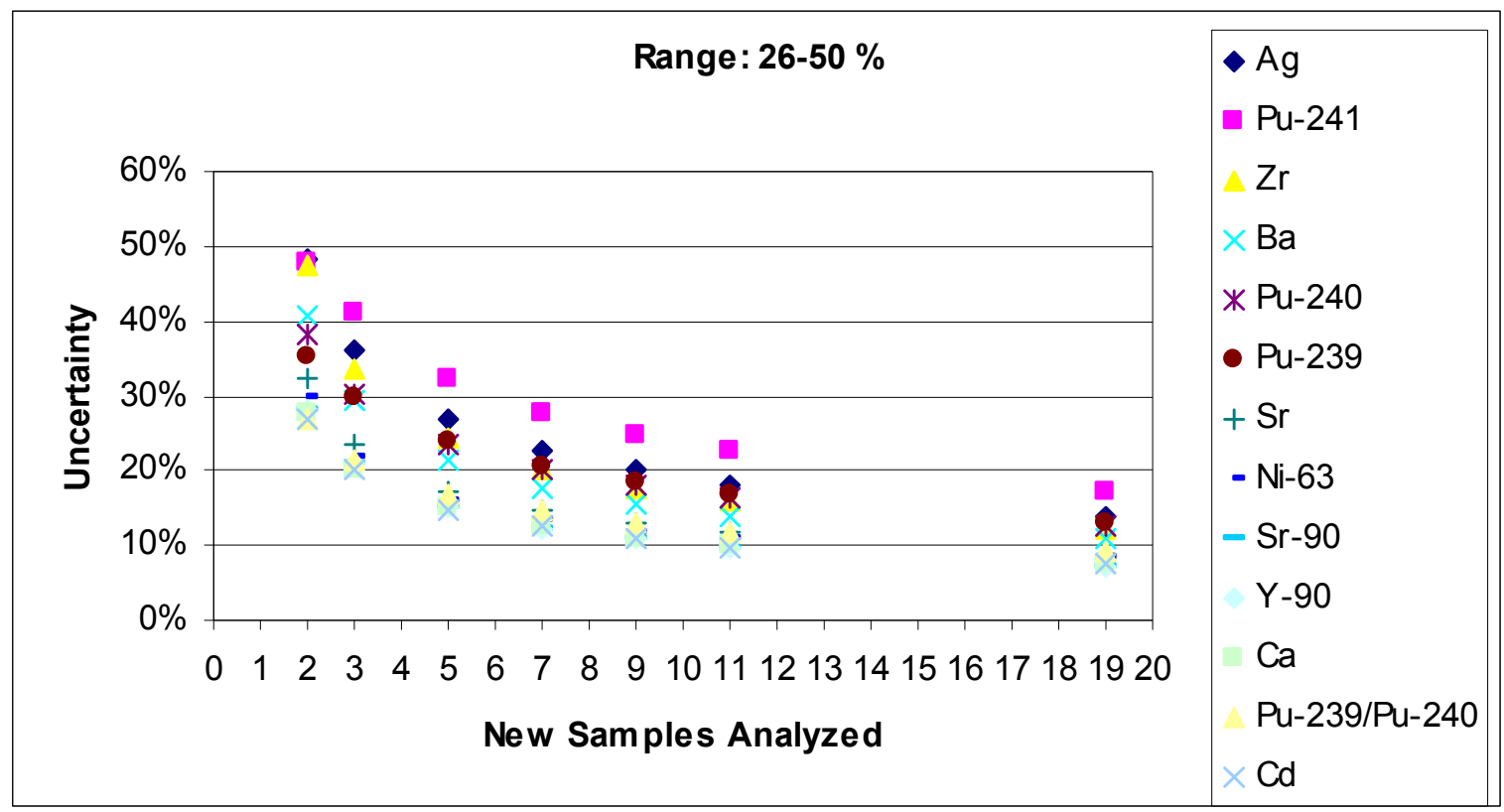

Figure 6. Uncertainty per Additional Samples (51-75\%) 


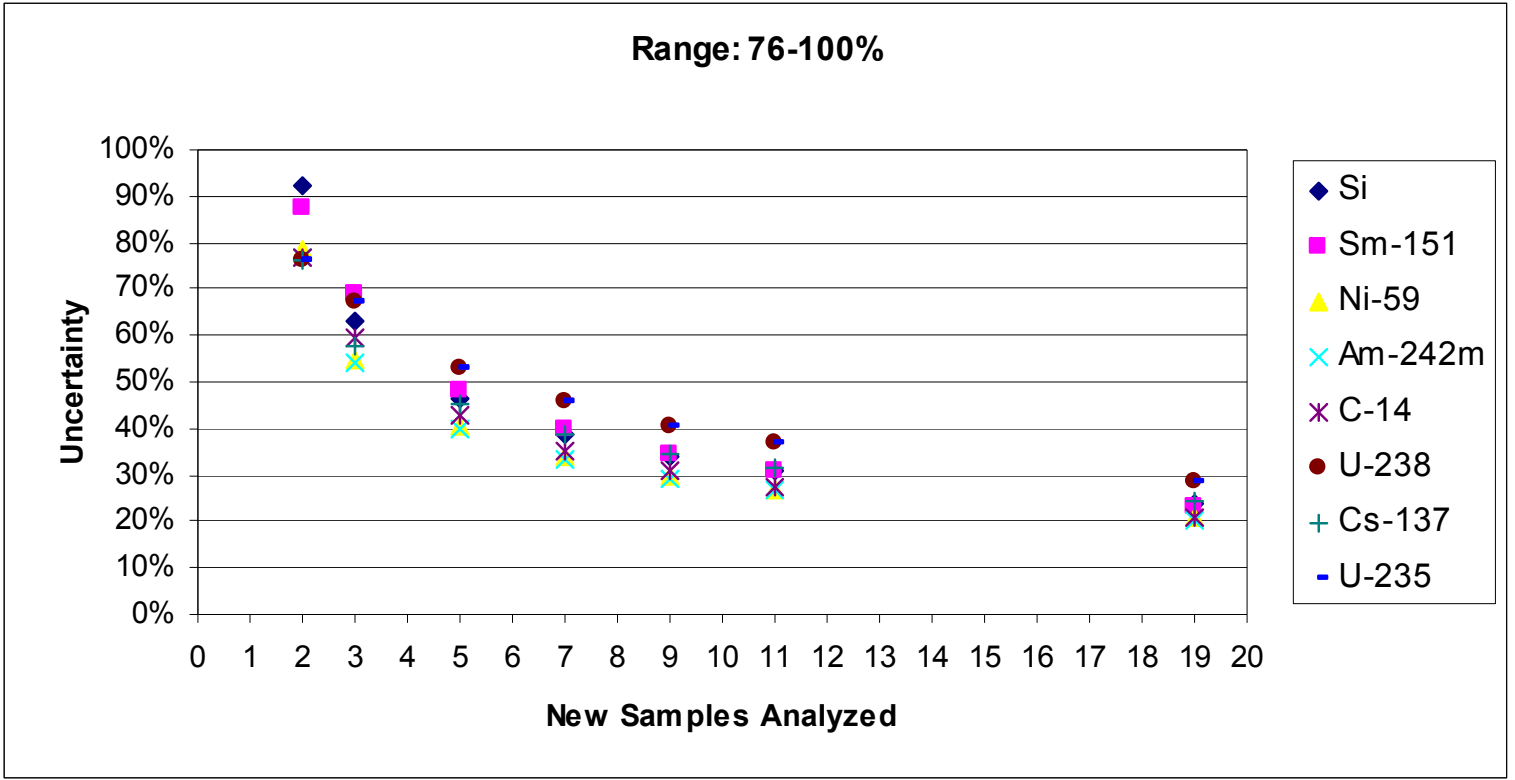

Figure 7. Uncertainty per Additional Samples (76-100\%)

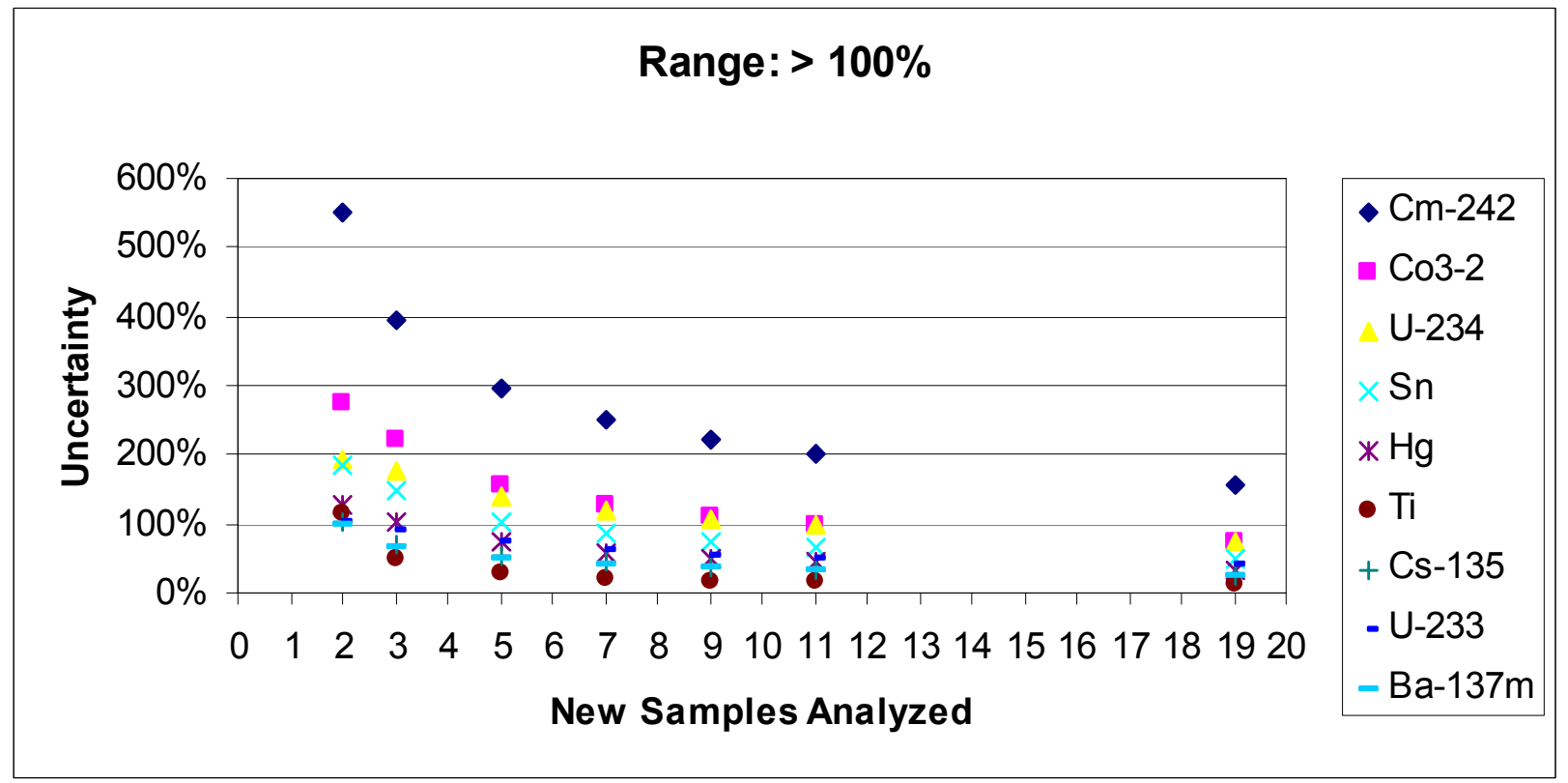

Figure 8. Uncertainty per Additional Samples (>100\%) 


\section{Distribution}

$\underline{\text { Savannah River Remediation }}$

B.A. Martin, 704-70F Closure and Waste Determination Authority

W.L. Isom, 704-26F Manager, Closure Project Engineering

G.D. Thaxton, 704-70F Closure Project Engineering

K.H. Barbour, 704-70F Type IV Tank Closure

J.E. Herbert, 241-108F Closure Projects

A.J. Tisler, 704-26F Closure Project Engineering

D.A. Broaden, 241-102F Type IV Tank Closure

G.C. Arthur, 704-70F Closure Project Engineering

D.J. Clark, 241-109F Bulk Sludge Removal

\section{$\underline{\text { Savannah River National Laboratory }}$}

F.M. Pennebaker, 773-42A Manager, Advanced Characterization \& Processing

P.L. Lee, 773-42A Manager, Applied Computational Engineering and Statistics

T. B. Edwards, 773-42A Applied Computational Engineering and Statistics

S.P. Harris, 773-42A Applied Computational Engineering and Statistics

S.J. Hensel, 773-42A Manager, Applied Computational Engineering and Sciences 